\title{
Efektivitas Metode Jigsaw Dibandingkan Metode Make a Match dalam Pengetahuan Personal Hygiene Saat Menstruasi: Studi Literatur
}

\author{
Ambo Sengngeng ${ }^{1}$, Herinawati ${ }^{2}$, Vivin Dianty ${ }^{3}$, Iksaruddin $^{4}$ \\ 1,2,3,4 Jurusan Kebidanan, Politeknik Kesehatan Kemenkes Jambi \\ *Correspondence email: herinawati_burhanuddin@yahoo.com
}

\begin{abstract}
Abstrak. Remaja mempunyai masalah terkait personal hygiene pada masa pubertas yang disebabkan oleh kurangnya pengetahuan penjelasan dan pelayanan kesehatan. Kebiasaan personal hygiene yang kurang baik dan dapat menyebabkan infeksi saluran reproduksi. Studi literarture ini adalah untuk menganalisa efektivitas metode jigsaw di bandingkan metode make a match dalam pengetahuan personal hygiene menstruasi pada remaja putri. Hasil pencarian yang didapat sebanyak 8 jurnal /artikel yang dianggap memiliki tujuan yang sama dengan judul penelitian. Adapun yang di review jurnal sebelum diberi jigsaw, sesudah diberi jigsaw, sebelum diberi make a match, sesudah diberi make a match. Hasil telaah jurnal peneliti menyatakan bahwa lebih efektiv metode kedua yaitu metode make a match dibandingkan metode jigsaw, dilihat dari peningkatan pengetahuan remaja setelah diberikan penyuluhan tentang kesehatan reproduksi personal hygiene saat menstruasi dan meningkat secara signifikan pada grafik penilaian dengan nilai statistik sebelum diberi jigsaw nilai 37,4\%, sesudah diberi jigsaw nilai statistik $73,5 \%$, sebelum diberi make a match 73,8\%, sesudah diberi make a match nilai statistik meningkat 75,8\%. Berdasarkan telaah jurnal lebih efektiv metode make a match dengan hasil nilai statistik $75,8 \%$ meningkat dilihat dari peningkatan pengetahuan responden. Dalam melakukan penyuluhan kesehatan reproduksi tentang personal hygiene saat menstruasi pada remaja dapat menggunakan metode make a match.
\end{abstract}

Kata kunci: metode jigsaw; metode make a match; personal hygiene; menstruasi

Abstract. Adolescents have problems related to personal hygiene at puberty due to a lack of knowledge of explanations and health services. Poor personal hygiene habits and can lead to reproductive tract infections. This literature study is to analyze the effectiveness of the jigsaw method compared to the make a match method in the knowledge of personal hygiene on menstruation in young women. The search results obtained were 8 journals and articles which were considered to have the same objectives as the research title. As for the journal review before being given a jigsaw, after being given a jigsaw, before being given a make a match, after being given a make a match. The results of the review of the research journal stated that the second method was more effective, namely the make a match method compared to the jigsaw method, seen from the increased knowledge of adolescents after being given counseling on reproductive health, personal hygiene during menstruation, and increasing significantly on the assessment graph with a statistical value before being given a jigsaw value of 37,4\%, after being given a jigsaw the statistical value of 73.5\%, before being given a make a match $73.8 \%$, after being given a make a match the statistical value increased by $75.8 \%$. Based on the review of journals, the make a match method is more effective with the result that the statistical value of 75.8\% increases as seen from the increase in respondents' knowledge. In providing reproductive health education about personal hygiene during menstruation for adolescents, the make a match method can be used.

Keywords: jigsaw method; make a match method; personal hygiene; Menstrual

\section{PENDAHULUAN}

Berdasarkan data WHO tahun 2010, angka kejadian infeksi saluran reproduksi (ISR) tertinggi di dunia adalah pada usia remaja (35\%-42\%) dan dewasa muda (27\%-33\%), angka prevalensi candidiasis (25$50 \%$ ). Berdasarkan data statistik di Indonesia tahun 2012 dar 43,3 juta jiwa remaja putri berusia 10-14 tahun berperilaku hygiene sangat buruk (Prayitno, 2014).

Pengetahuan seseorang tentang personal hygiene juga memiliki pengaruh bagi perilaku seseorang dalam menjaga dan merwat kesehatan reproduksinya. Pendidikan kesehatan tentang kesehatan reproduksi penting untuk remaja agar mereka mempunyai informasi dan pengetahuan yang benar tentang kesehatan reproduksi. Di Indonesia, prevalensi terjadinya infeksi saluran reproduksi akibat kurang nya hygiene pada organ genitalia masih cukup tinggi, jumlah penderita infeksi saluran reproduksi di Indonesia adalah 90-100 kasus per 100.000 penduduk pertahun (Depkes RI, 2014).

Berdasarkan Survei Kesehatan Reproduksi Remaja Indonesia (SKKRI) tahun 2007 bahwa secara nasional remaja yang berperilaku hygiene dengan benar sebesar 21,6\%. Sedangkan menurut Survei Demografi Kesehatan Indonesia (SDKI), perilaku remaja putri dalam menjaga hygiene menstruasi masih buruk, yaitu $69,3 \%$. Penyebab karena kurangnya pemahaman personal hygiene genitalia adalah terjadinya gangguan kesehatan reproduksi seperti keputihan, infeksi saluran reproduksi (ISR), penyakit radang panggul dan kemungkinan terjadi kanker leher rahim (Wakhidah, 2014). Provinsi jambi memiliki prevalensi kanker serviks $1,5 \%$. Menurut karakteristik terlihat pravelensi kanker meningkat pada usia $>15$ tahun dan tertinggi pada umur $>75$ tahun (5\%) Riskesdes Provinsi Jambi, (2018). 
Remaja mempunyai masalah terkait personal hygiene pada masa pubertas yang disebabkan oleh kurangnya penjelasan dan pelayanan jasa kesehatan personal hygiene pada saat menstruasi pada remaja. Kebiasaaan personal hygiene yang kurang baik dan dapat menyebabkan infeksi saluran reproduksi (Fitriyah, 2014) masih sering dilakukan remaja seperti menggunakan sabun mandi untuk membersihkan organ genitalia, tidak mengganti pembalut 4 kali sehari dan menggunakan celana yang ketat saat menstruasi.

Pendidikan kesehatan berperan besar terhadap peningkatan pengetahuan dan personal hygiene pada remaja putri. Remaja pada umumnya malu jika membahas personal hygiene menstruasi dimana penyuluhan tentang menjaga kebersihan alat kelamin saat menstruasi pun tidak pernah mereka dapatkan (Zakir, 2016). Pengetahuan tentang menstruasi umumnya hanya diberikan pada mata pelajaran biologi di sekolah tanpa mendalami mengenai personal hygiene menstruasi yang tepat pada remaja. Pengetahuan tentang tindakan personal hygiene dapat menjadi penyebab terjadinya infeksi saluran reproduksi jika tidak diatasi. Santra, (2017) berpendapat bahwa peningkatan pengetahuan sangat penting untuk dilakukan karena dapat mempengaruhi tindakan pemeliharaan hygiene saat menstruasi.

Tingkat pengetahuan antara remaja putri satu dengan yang lainnya berbeda-beda, termaksud pengetahuan mengenai cara membersihkan genitalia saat menstruasi, sehingga akan mempengaruhi sikap dan tindakan menjaga kebersihan genitalia saat menstruasi. Pengetahuan yang rendah cendrung memiliki sikao dan tindakan yang kurang sesuai. Hal tersebut sesuai dengan pendapat L. Green (1983) bahwa perilaku seseorang dapat dipengaruhi oleh pengetahuan yang dimilikinya (Notoatmodjo, 2010).

Selama ini proses pembelajaran lebih terpusat pada guru sedangkan siswa mendengarkan secara pasif. Proses pembelajaran ini akan menjadikan siswa mudah bosan, dan kurang aktif saat menerima materi. Cooperative learning merupakan model pembelajran kolabiratif yang mengutamakan keaktifan siswa untuk mencapai suatu tujuan bersama. Model cooperative learning yang mengutamakan partisipasi siswa yaitu metode Jigsaw dan metode Make a Match. Metode pembelajaran jigsaw merupakan salah satu medel cooperative learning yang dapat menekankan pada kerja sama antar anggota kelompok yang dapat meningkatkan pengetahuan, sikap, dan keterampilan tiap anggota kelompok secara independen dan kolaboratif (LeyvaMoral \& Riu Camps, 2016).

Sedangkan metode Make a Match merupakan model pembelajaran cooperative learning yang bertujuan agar para siswa dapat berperan aktif dalam proses pembelajaran yang menyenangkan dan berdiskusi dengan individu lain mengenai suatu permasalahan (Hidayah. N., Suharno, 2016). Dengan adanya proses diskusi tersebut, terjadi proses komunikasi yang persuasive yang bertujuan untuk mengubah kepercayaan, sikap, dan perilaku seseorang sesuai tugas perkembangan remaja. Kedua metode pembelajaran ini mampu mengembangkan keterampilan komunikasi dan bersosialisasi remaja baik secara individu maupun kelompok, dan menerima dirinya sendiri, serta memiliki kepercayaan terhadap kemampuannya sendiri.

\section{METODE \\ Desain Penelitian}

Desain penelitian ini adalah Literature Reviw atau tinjauan pustaka. Studi literature review adalah cara yang dipakai untuk mengumpulkan data atau sumber yang berhubungan pada sebuah topik tertentu yang bisa di dapat dari berbagai sumber seperti jurnal, buku, internet, dan pustaka lain. Metode serangkaian kegiatan yang berkenaan dengan metode pengumpulan data pustaka, membaca dan mencatat, serta mengelola bahan penelitian. Dengan melakukan studi perpustakaan, para peneliti mempunyai pendalaman yang lebih luas dan mendalam tentang efektivitas metode jigsaw di bandingkan metode make a match dalam pengetahuan personal hygiene menstruasi pada remaja putri di Indonesia. Data yang didapat dari studi literature ini akan digunakan sebagai acuan untuk membuat analisis penelitian.

\section{Jenis Data}

Data yang digunakan adalah data sekunder yang diperoleh dari jurnal, buku, dokumentasi, dan internet. Data-data atau sumber-sumber yang dikumpulkan berhubungan dengan topik yang diangkat dalam suatu penelitian.

\section{Meode Pengumpulan Literature}

Peneliti menentukan rancangan penelitian yang paling tepat untuk mencapai tujuan penelitiannya, subyek penelitian yang paling sesuai, cara mengidentifikasi dan menjaringnya, cara mengumpulkan data dan informasi, dan cara mengelola dan mengolah data yang dikumpulkan. Selain buku-buku metodologi penelitian, peniliti juga perlu membaca laporan-laporan penelitian mengenai topik yang serupa ataupun penelitian dengan kelompok masyarakat yang serupa.

\section{Kriteria Inklusi dan Eksklusi:}

\section{Tipe Study}

Desain penelitian yang diambil dalam penelusuran ilmiah ini adalah experimental studi, survey studi, analisis korelasi, analisis komparasi, kualitatif studi.

2. Tipe Intervensi

Intervensi pertama yang ditelaah pada penelusuran ilmiah ini adalah efektivitas metode jigsaw di bandingkan metode make a match dalam pengetahuan personal hygiene menstruasi pada remaja putri di Indonesia. 
3. Hasil Ukur

Outcome yang diukur dalam penelusuran ilmiah ini adalah efektivitas metode jigsaw di bandingkan metode make a match dalam pengetahuan personal hygiene menstruasi pada remaja putri di Indonesia.

4. Strategi Pencarian Literature
Jurnal-jurnal uang dipilih adala semua penelitian yang mencangkup dengan efektivitas metode jigsaw di bandingkan metode make a match dalam pengetahuan personal hygiene menstruasi pada

\section{HASIL DAN PEMBAHASAN Hasil Literatur}

Tabel 1. Matriks Penelitian

\begin{tabular}{|c|c|c|c|c|}
\hline No & Judul, Penulis, Tahun & Fenomena & Variabel Yang Diteliti & Hasil Penelitian \\
\hline 1. & $\begin{array}{l}\text { Judul : } \\
\text { Pendidikan kesehatan jigsaw } \\
\text { dan make a match dalam } \\
\text { mencegah flour albus pada } \\
\text { remaja pondok. } \\
\text { Penulis : } \\
\text { Laili Bestari Putri, dkk. } \\
\text { Tahun : } \\
\text { 2019. }\end{array}$ & $\begin{array}{l}\text { Pengaruh Pendidikan Kesehatan Metode } \\
\text { Jigsaw dan Make a Match terhadap } \\
\text { Pengetahuan Pencegahan Fluor albus pada } \\
\text { Remaja } \\
\text { Pendidikan kesehatan metode Jigsaw } \\
\text { berpengaruh terhadap pengetahuan } \\
\text { pencegahan fluor albus pada responden. } \\
\text { Pengetahuan responden meningkat setelah } \\
\text { mendapatkan pendidikan kesehatan dengan } \\
\text { menggunakan metode Jigsaw disebabkan } \\
\text { karenaposttest sebanyak } 25 \text { remaja }(69,4 \%)\end{array}$ & $\begin{array}{l}\text { a. Pendidikan kesehatan } \\
\text { metode Jigsaw dan Make a } \\
\text { Match } \\
\text { b. Perilaku pencegahan } \\
\text { fluor albus pada remaja } \\
\text { pondok pesantren }\end{array}$ & $\begin{array}{l}\text { Pengetahuan remaja pada kelompok Jigsaw } \\
\text { saat pretest sebagian besar berpengetahuan } \\
\text { kurang, yaitu sebanyak } 17 \text { remaja }(47,2 \%) \text {, } \\
\text { saat posttest sebanyak } 28 \text { remaja }(77,8 \%) \\
\text { berpengetahuan baik. pada kelompok Make } \\
\text { a Match saat pretest sebagian besar } \\
\text { berpengetahuan kurang, yaitu sebanyak } 15 \\
\text { remaja }(41,7 \%) \text { sedangkan saat posttest } \\
\text { sebanyak } 20 \text { remaja }(55,6 \%) \\
\text { berpengetahuan baik. }\end{array}$ \\
\hline
\end{tabular}

2. Judul :

Efektivitas Pelatihan Kader Posyandu Dalam Penggunaan Buku KIA Dengan Metode Make a Match

Penulis :

Dewi Zolekhah, Elvika Fit Ari Shanti, Liberty Barokah Tahun : 2019

3. Judul :

Cooperative learning in third graders' jigsaw groups for mathematics and science with and without questioning training Penulis :

Elmar. Souvignier Tahun :

2008

4. Judul :

Effectiveness of Jigsaw learning compared to lecture-based learning in dental education.

Penulis :

Turel M. Yildiz E. Kaya

Tahun :

2015
There is much support for using cooperative methods, since important instructional aspects, such as elaboration of new information, can easily be realized by methods like 'jigsaw'. However, the impact of providing students with additional help like a questioning training and potential limitations of the method concerning the (minimum) age of the students have rarely been investigated.

The objective of this study was to evaluate the success levels of students using the Jigsaw learning method in dental education

\section{a.Pelatihan \\ b. Kader \\ c. Buku KIA}

Jigsaw method

Method Jigsaw
Karakteristik responden berdasarkan umur sebagian besar adalah usia > 35 tahun sebesar 53,3\%. Karaketeristik responden berdasarkan

pendidikan sebagian besar adalah SMA sebesar $80 \%$ dan karakteristik responden berdasarkan pekerjaan sebagian besar adalah IRT 83,33\% . pengetahuan kader sebelum diberikan

pelatihan dalam kategori baik 1 orang $(3,3 \%)$ setelah diberikan pelatihanmeningkat menjadi 20 orang $(66,7 \%)$. berdasarkan hasil wilcoxon menunjukkan bahwa ada perbedaan yang bermakna $(\mathrm{p}=0.000<\propto)$ pengetahuan kader sebelum dan sesudah diberikan pelatihan tentang penggunaan Buku KIA Dengan Metode Make A Match

In the math units, no differences between the three conditions could be detected. In the astronomy unit, students benefited more from teacher-guided instruction.

Differential analyses revealed that 'experts' learned more than students in teacherguided instruction, whereas 'novices' were outperformed by the students in the control classes.

Fifty students with similar grade point average (GPA) scores were selected and randomly assigned into one of two groups $(n=25)$. A pretest concerning 'adhesion and bonding agents in dentistry' was administered to all students before classes. The Jigsaw learning method was applied to the experimental group for 3 weeks. At the same time, the control group was taking classes using the lecture-based learning method. At the end of the 3 weeks, all students were retested (post-test) on the subject. A retention test was administered 3 weeks after the post-test. Mean scores were calculated for each test for the experimental and control groups, and the data obtained were analysed using the independent samples $t$-test.

Dari 88 responden terdapat 67 responden $(76,1 \%)$ dengan model pembelajaran jigsaw baik
a.Metode jigsaw
b. Hasil pembelajaran
Metode pembelajaran adalah suatu cara atau upaya yang dilakukan oleh para pendidik agar 
jigsaw terhadap

Hasil belajar mata kuliah

asuhan kebidanan komunitas

Penulis :

Sumarni, Hasbiah Wardani

Tahun :

2019 proses belajar-mengajar pada mahasiswa tercapai sesuai dengan tujuan. Metode pembelajaran

ini sangat penting dilakukan agar proses belajar mengajar tersebut nampak menyenangkan dan

tidak membuat para mahasiswa tersebut suntuk, dan juga para mahasiswa Berdasarkan hasil analisis Chi- square diperoleh nilai $\mathrm{p}$ $=0,000<0,05$ sehingga Ho di tolak dan $\mathrm{Ha}$ diterima. Maka

dapat disimpulkan bahwa ada pengaruh model pembelajaran kooperatif tipe jigsaw terhadap

hasil belajar mata kuliah asuhan kebidanan komunitas Prodi D-III kebidanan STIKes Mega

Resky Makassar Tahun 2018.

Sesuai dengan hasil penelitian (Rosyidah, 2016)

Perilaku kesehatan pada remaja saat menstruasi diawali dengan menjaga kebersihan organ kewanitaan. Akibat kurangnya menjaga kebersihan alat genetalia dapat mengakibatkan timbulnya Infeksi Saluran Reproduksi (ISR) yang dapat terjadi tidak hanya ditemukan pada pekerja seks komersial melainkan sudah banyak ditemukan pada wanita remaja.
7. Judul :

Penggunaan model cooperative learning type make-a-match terhadap hasil belajar sistem gerak

Penulis :

Irma Paramita

Tahun :

2012

8. Judul :

Keefektifan cooperative learning tipe jigsaw dan STAD ditinjau dari prestasi belajar dan kepercayaan diri siswa

Penulis :

Curie Putri Hijrihani

Tahun :

2015
a.Pengetahuan $\mathrm{b}$.

Kebersihan alat genetalia

c. Remaja

Metode make a match

Penggunaan suatu model pembelajaran yang tepat yang dapat meningkatkan keterlibatan siswa dalam pembelajaran.

Salah satu model pembelajaran seperti yang dimaksud adalah model pembelajaran

kooperatif tipe make a match

Penelitian ini untuk mendeskripsikan keefektifan model pembelajaran kooperatif tipe Jigsaw dan Student Teams Achievement Divisions (STAD) ditinjau dari prestasi belajar dan kepercayaan diri siswa SMP

Metode jigsaw yang terdiri dari 64 responden atau (100\%) dengan hasil belajar baik dan 3 responden $(12,5 \%)$

dengan hasil belajar kurang sedangkan dari 21 responden dengan model pembelajaran kooperatif kurang terdiri dari 0 responden $(0 \%)$ dengan hasil belajar kurang dan 21responden

$(87,5 \%)$ dengan hasil belajar kurang. Metode pembelajaran adalah suatu cara atau upaya yang dilakukan oleh para pendidik agar

proses belajar-mengajar pada mahasiswa tercapai sesuai dengan tujuan. Metode pembelajaran

ini sangat penting dilakukan agar proses belajar mengajar tersebut nampak menyenangkan dan

tidak membuat para mahasiswa tersebut suntuk, dan juga para mahasiswa

Berdasarkan hasil

analisis Chi- square diperoleh nilai $\mathrm{p}$ $=0,000<0,05$ sehingga Ho di tolak dan $\mathrm{Ha}$ diterima. Maka

dapat disimpulkan bahwa ada pengaruh model pembelajaran kooperatif tipe jigsaw terhadap

hasil belajar mata kuliah asuhan kebidanan komunitas

Hasil penelitian gambaran pengetahuan remaja tentang kebersihan alat genetalia pada saat menstruasi yang dilakukan pada 112 responden diketahui sebagian besar responden 40,2\% memiliki pengetahuan baik, $34.5 \%$ memiliki pengetahuan cukup, dan $25,3 \%$ memiliki pengetahuan kurang dalam menjaga kebersihan alat genetalia pada saat menstruasi di SMAGajah Mada Bandar Lampung. Peneliti menyarankan bagi dewan guru di SMAGajah Mada Bandar Lampung agar lebih meningkatkan pengetahuan mengenai kebersihan alat genetalia pada saat menstruasi serta mengajarkan kepada siswi melalui mata pelajaran biologi.

Penggunaan model pembelajaran cooperative learning type make-a-match yang dilengkapi dengan media evidence card berpengaruh terhadap peningkatan hasil belajar siswa SMA N 1 Ambarawa kelas XI semester gasal materi sistem gerak manusia.

Pembelajaran kooperatif tipe Jigsaw dan tipe STAD tidak efektif ditinjau dari prestasi belajar siswa, akan tetapi efektif ditinjau dari kepercayaan diri siswa.

\section{Analisis Data}

Hasil review 8 literatur atau jurnal yang dilakukan penulis di dapatkan hasil yaitu sebelum di lakukan atau diberikan metode jigsaw dan make a match. Hal ini di pengaruhi oleh pengetahuan responden terhadap personal hygiene saat menstruasi.

Berdasarkan hasil literature dapat dianalisa sebagai berikut:
Tabel 2. Sebelum diberikan metode pembelajaran jigsaw

\begin{tabular}{llll}
\hline No & Pengarang & Sampel & \multicolumn{1}{c}{ Hasil } \\
\hline 1. & Laili Bestari & 108 orang & Pengetahuan remaja \\
& Putri, dkk. & & pada kelompok Jigsaw \\
& 2019 & & saat pretest sebagian \\
& & besar berpengetahuan \\
& & kurang, yaitu sebanyak \\
& & & 17 remaja $(47,2 \%)$
\end{tabular}




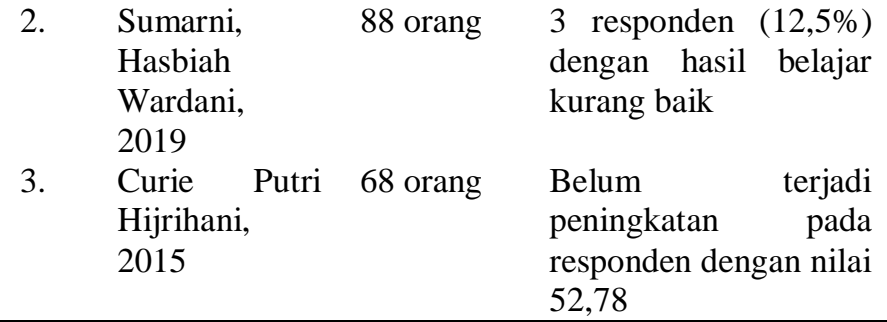

Analisis jurnal diatasbahwa terdapat sampel pertama yaitu 108 responden, pada jurnal kedua 88 responden, dan pada jurnal ketiga dengan sampel 68 responden dengan hasil rata-rata sampel sebanyak 88 responden. Pada hasil nilai jurnal pertama sebesar $47,2 \%$, pada hasil jurnal kedua $12,5 \%$, dan pada hasil jurnal ketiga sebesar $52,78 \%$ sehingga didapatkan hasil nilai rata-rata statistik $37,4 \%$ pengetahuan responden kurang baik ditinjau dari pengetahuan sebelum diberikan metode pembelajaran jigsaw.

Tabel 3. Sesudah diberikan pengetahuan jigsaw

\begin{tabular}{|c|c|c|c|}
\hline No & Pengarang & Sampel & Hasil \\
\hline 1. & $\begin{array}{l}\text { Laili Bestari Putri, } \\
\text { dkk. } 2019\end{array}$ & 108 orang & $\begin{array}{l}28 \text { remaja } \\
(77,8 \%) \\
\text { berpengetahuan } \\
\text { baik }\end{array}$ \\
\hline 2. & $\begin{array}{l}\text { Sumarni, Hasbiah } \\
\text { Wardani, } 2019\end{array}$ & 88 orang & $\begin{array}{l}67 \text { responden } \\
(76,1 \%) \text { dengan } \\
\text { model } \\
\text { pembelajaran } \\
\text { jigsaw baik }\end{array}$ \\
\hline 3. & $\begin{array}{l}\text { Curie Putri } \\
\text { Hijrihani, } 2015\end{array}$ & 68 orang & $\begin{array}{l}\text { Terjadi } \\
\text { peningkatan nilai } \\
\text { rata-rata untuk } \\
\text { pembelajaran } \\
\text { dengan jigsaw } \\
\text { yaitu } 66,67 \text {. }\end{array}$ \\
\hline
\end{tabular}

Hasil analisis jurnal diatas bahwa terdapat sampel pada jurnal pertama yaitu 108 responden, pada jurnal kedua 88 responden, dan pada jurnal ketiga dengan sampel 68 responden dengan hasil rata-rata sampel sebanyak 88 responden. Pada hasil nilai jurnal pertama sebesar 47,2\%, pada hasil jurnal kedua 12,5\%, dan pada hasil jurnal ketiga sebesar $52,78 \%$ sehingga didapatkan hasil nilai rata-rata statistik $73,5 \%$ terjadi peningkatan yang sangat signifikan terhadap pengetahuan sesudah di berikan metode pembelajaran jigsaw.

Tabel 4. Sebelum diberikan metode pembelajaran make a match

\begin{tabular}{|c|c|c|c|}
\hline No & Pengarang & Sampel & Hasil \\
\hline 1. & $\begin{array}{l}\text { Dewi Zolekhah, } \\
\text { Elvika Fit } \text { Ari Shanti, } \\
\text { Liberty Barokah, } 2019\end{array}$ & 30 orang & $\begin{array}{l}\text { Sebelum } \\
\text { diberikan } \\
\text { pelatihan daalam } \\
\text { kategori baik } 1 \\
\text { orang }(3,3 \%)\end{array}$ \\
\hline 2. & Irma Paramita, 2012 & 47 orang & $\begin{array}{l}50 \% \text { siswa yang } \\
\text { berpengetahuan } \\
\text { kurang baik. }\end{array}$ \\
\hline
\end{tabular}

Hasil telaah jurnal diatas terdapat sampel pada jurnal pertama sebanyak 30 responden dan pada jurnal kedua sebanyak 47responden sehingga hasil rata-rata sebanyak 77 sampel. Pada jurnal kedua dengan nilai 3,3\% dan pada jurnal kedua dengan hasil nilai sebesar $50 \%$ sehingga dengan hasil nilai rata-rata statistik $73,8 \%$ berpengetahuan kurang baik.

Tabel 5. Sesudah diberi metode pembelajaran make a match

\begin{tabular}{llrl}
\hline No & \multicolumn{1}{c}{ Pengarang } & Sampel & \multicolumn{2}{c}{ Hasil } \\
\hline 1. & Dewi Zolekhah, Elvika 30 orang & Meningkat \\
& $\begin{array}{l}\text { Fit Ari Shanti, Liberty } \\
\text { Barokah, 2019 }\end{array}$ & & $\begin{array}{l}\text { menjadi } \\
\text { orang } \\
(66,7 \%) .\end{array}$ \\
& & 47 orang & $\begin{array}{l}\text { Meningkat } \\
\text { menjadi } \\
(85 \%)\end{array}$ \\
\hline
\end{tabular}

Hasil telaah jurnal diatas terdapat sampel pada jurnal pertama sebanyak 30 responden dan pada jurnal kedua sebanyak 47 responden sehingga hasil rata-rata sebanyak 77 sampel. Pada jurnal kedua dengan nilai $66,7 \%$ dan pada jurnal kedua dengan hasil nilai sebesar $85 \%$ sehingga dengan hasil nilai rata-rata statistik $75,8 \%$ berpengetahuan kurang baik.

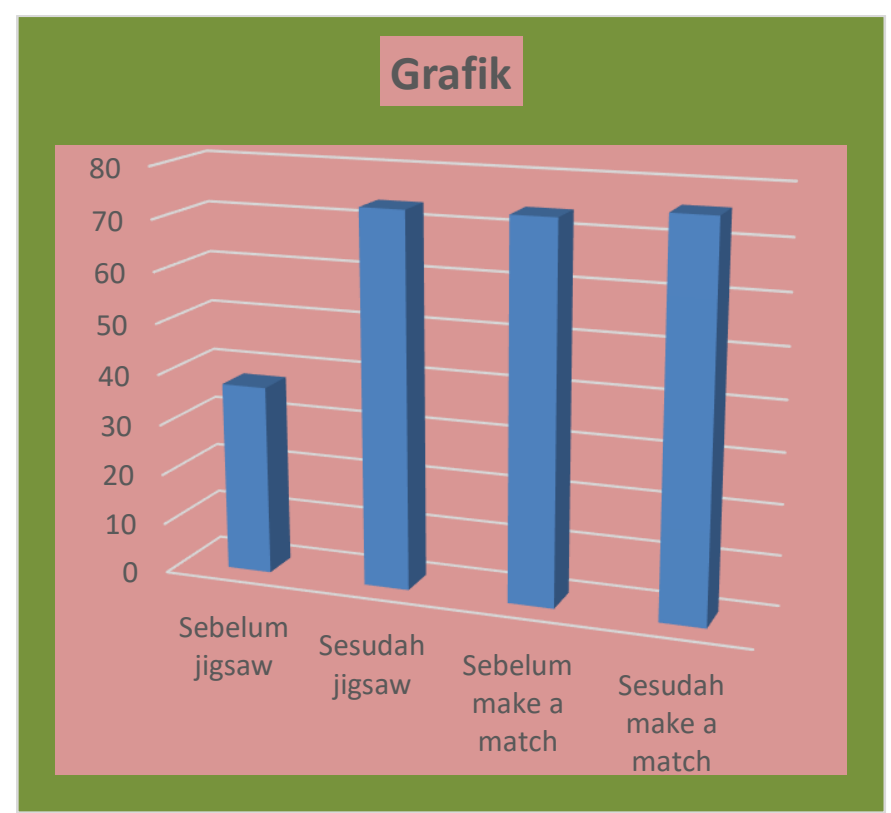

Gambar 1. Hasil review 8 literatur atau jurnal yang dilakukan penulis di dapatkan hasil yaitu sebelum di lakukan atau diberikan metode jigsaw dan make a match

Hasil grafik diatas dapat disimpulkan bahwa telah terjadi peningkatan secara signifikan terhadap nilai kedua metode, yang pertama metode jigsaw sebelum diberikan terdapat nilai rata-rata 37,4\% kemudian setelah diberikan metode jigsaw terjadi kenaikan nilai rata-rata $73,5 \%$. Kemudian metode kedua yaitu metode make a match sebelum diberikan terdapat nilai rata-rata $73,8 \%$ setelah diberikan metode make a match terjadi kenaikan nilai rata-rata $75,8 \%$. Penulis menyimpulkan bahwa 
lebih efektiv metode kedua yaitu metode make a match dilihat dari kenaikan nilai grafik diatas dan dilihat dari peningkatan pengetahuan responden.

\section{Pembahasan}

Dari delapan jurnal yang dipilih seluruhnya meneliti tentang efektifitas metode jigsaw dan metode make a match dalam meningkatkan perilaku personal hygiene saat menstruasi pada remaja putri adapun pembehasan sebagai berikut :

1. Berdasarkan penelitian dari beberapa jurnal diatas hasil analisis sebelum diberi metode pembelajaran jigsaw sebagai berikut :

a. Berdasarkan penelitian pertama yang dilakukan oleh Laili Bestari Putri dkk (2019) tentang pendidikan kesehatan jigsaw dan make a match dalam mencegah flour albus pada remaja pondok pesantren dengan sampe 108 orang. Hasil statistik di dapatkan pengetahuan remaja pada kelompok pretest sebagian besar berpengetahuan kurang baik, yaitu sebanyak 17 remaja $(47,2 \%)$.

b. Penelitian yang kedua oleh Sumarni, Hasbiah Wardani (2019) tentang Pengaruh model pembelajaran kooperatif tipe jigsaw terhadap hasil belajar mata kuliah asuhan kebidanan komunitas. Sampel dalam penelitian ini sebanyak 88 orang. Terdapat hasil kurang baik sebanyak 3 responden $(12,5 \%)$

c. Penelitian ketiga oleh Curie Putri Hijrihani (2015) Keefektifan cooperative learning tipe jigsaw dan STAD ditinjau dari prestasi belajar dan kepercayaan diri siswa. Dengan sampel 2 kelas dari 4 kelas yang terpilih, hasil penelitian menunjukkan belum terjadi peningkatan pada responden dengan nilai $52,78 \%$.

Hasil dari dari 88 sampel yang diteliti dengan nilai statistik $37,4 \%$ remaja cendrung memiliki pengetahuan yang kurang baik tentang kesehatan reproduksi personal hygiene dikarenakan responden memiliki sumber pengetahuan yang kurang memadai karna mereka hanya mendapatkan informasi dari teman sebaya (Data PKBI dalam Mardiana, 2016) sehingga remaja tersebut perlu diberikan penyuluhan tentang kesehatan repsoduksi tepatnya pada personal hygiene saat menstruasi dengan menggunakan metode jigsaw.

2. Berdasarkan beberapa jurnal diatas penulis dapat menyimpulkan penelitian sesudah diberi pengetahuan metode jigsaw.

a. Berdasarkan penelitian pertama yang dilakukan olehLaili Bestari Putri dkk (2019) tentang pendidikan kesehatan jigsaw dan make a match dalam mencegah flour albus pada remaja pondok pesantren dengan sampe 108 orang. Hasil statistik terjadi peningkatan pengetahuan setelah dilakukan pemberian metode jigsaw yaitu dengan nilai posttest 28 remaja $(77,8 \%)$ berpengetahuan baik.

b. Penelitian yang kedua oleh Sumarni, Hasbiah Wardani (2019) tentang Pengaruh model pembelajaran kooperatif tipe jigsaw terhadap hasil belajar mata kuliah asuhan kebidanan komunitas. Sampel dalam penelitian ini sebanyak 88 orang. Terdapat peningkatan hasil 67 responden $(76,1 \%)$.

c. Penelitian ketiga oleh Curie Putri Hijrihani (2015) Keefektifan cooperative learning tipe jigsaw dan STAD ditinjau dari prestasi belajar dan kepercayaan diri siswa. Dengan sampel 2 kelas dari 4 kelas yang terpilih sebanyak 68 orang. Terjadi peningkatan hasil rata-rata untuk pembelajaran dengan jigsaw yaitu $66,67 \%$, sehingga didapatkan nilai $\mathrm{p}=1,93$ yang berarti pembelajaran tipe jigsaw efektif ditunjau dari kepercyan diri responden tersebut.

Hasil analisis metode jigsaw setelah diberikan pada responden dalam penyuluhan tentang kesehatan reproduksi pada personal hygiene saat menstruasi meningkat dengan nilai statistik $73,5 \%$. Peningkatan pengetahuan responden sebelum diberi metode jigsaw dan sesudah diberi metode jigsaw meningkat sebesar $36,1 \%$ sehingga banyak responden yang lebih paham tentang kesehatan repsoduksi personal hygiene saat menstruasi pada remaja setelah diberi penyuluhan dengan menggunakan metode jigsaw.

3. Berdasarkan jurnal diatas penulis dapat menyimpulkan beberapa jurnal yang belum diberikan metode make a match :

a. Berdasarkan penelitian pertama oleh Dewi Zolekhah dkk (2019) yang berjudul tentang efektivitas pelatihan kader posyandu dalam penggunaan bukukia dengan metode make a match. Dengan sampel sebanyak 30 orang. Sebelum diberikan pelatihan dalam kategori baik 1 orang $(3,3 \%)$.

b. Penelitian kedua oleh Irma Paramita (2012) yang berjudul tentang Penggunaan model cooperative learning type make-a-match terhadap hasil belajar sistem gerak. Dengan sempel semua siswa yang bersangkutan sebanyak 47 responden. Hasil penelitian didapatkan $50 \%$ siswa yang berpengetahuan kurang baik.

Hasil dari 77 sampel yang diteliti dengan nilai statistik $73,8 \% \%$ remaja cendrung memiliki pengetahuan yang kurang baik tentang kesehatan reproduksi personal hygiene dikarenakan responden memiliki sumber pengetahuan yang kurang memadai karna mereka hanya mendapatkan informasi dari teman sebaya (Data PKBI dalam jurnal Mardiana, 2016) sehingga remaja tersebut perlu diberikan penyuluhan tentang kesehatan repsoduksi tepatnya pada 
personal hygiene saat menstruasi dengan menggunakan metode make a match.

4. Berdasarkan jurnal diatas penulis dapat menyimpulkan hasil sesudah diberi metode pembelajaran make a match sebagai berikut :

a. Berdasarkan penelitian pertama oleh Dewi Zolekhah dkk (2019) yang berjudul tentang efektivitas pelatihan kader posyandu dalam penggunaan bukukia dengan metode make a match. Dengan sampel sebanyak 30 orang. Setelah diberikan metode make match meningkat menjdi $(66,7 \%)$.

b. Penelitian kedua oleh Irma Paramita (2012) yang berjudul tentang Penggunaan model cooperative learning type make-a-match terhadap hasil belajar sistem gerak. Dengan sempel semua siswa yang bersangkutan sebanyak 47 responden. Setelah diberikan metode make a match meningkat dari $50 \%$ menjadi $85 \%$ responden berpengetahuan sangat baik.

Hasil analisis metode make a match yang diberikan pada 77 sampel yang diteliti telah terjadi peningkatan pengetahuan terhadap responden setelah diberikan penyuluhan tentang kesehatan reproduksi personal hygiene saat menstruasi dengan menggunakan metode make a match, sebelum diberi pengetahuan nilai statistik sebesar 73,8\% kemudian setelah diberikan metode make a match pengetahuan responden meningkat menjadi 75,8\%. Peningkatan pengetahuan sebelum dan sesudah diberikan metode make a match sebesar $2 \%$ sehingga banyak responden yang lebih paham dengan materi setelah diberikan penyuluhan tentang kesehatan reproduksi personal hygiene saat menstruasi menggunakan metode make a match.

5. Perbandingan antara kedua metode pembelajaran tipe jigsaw dan metode pembelajaran tipe make a match bahwa lebih efektiv metode kedua yaitu metode make a match dibandingkan metode jigsaw, dilihat dari peningkatan pengetahuan remaja setelah diberikan penyuluhan tentang kesehatan reproduksi personal hygiene saat menstruasidan meningkat secara signifikan pada grafik penilain dengan nilai statistik $75,8 \%$ peningkatan terjadi karena metode make a match merupakan metode pembelajaran dengan tehnik fasilitator memberikan kertas soal dan jawaban pada responden kemudian responden saling bekerja sama untuk menemukan soal dan jawaban yang cocok, sehingga metode make a match dapat meningkatkan aktifitas responden dalam proses belajar.

\section{SIMPULAN}

a. Sebelum diberikan metode jigsaw hasil nilai rata-rata statistik 37,4\% pengetahuan responden kurang baik ditinjau dari pengetahuan sebelum diberikan metode pembelajaran jigsaw.

b. Sesudah diberikan metode jigsaw hasil nilai rata-rata statistik $73,5 \%$ terjadi peningkatan yang sangat signifikan terhadap pengetahuan remaja tentang kesehatan reproduksi personal hygiene saat menstruasi sesudah di berikan metode pembelajaran jigsaw.

c. Sebelum diberikan metode make a match hasil nilai rata-rata statistik $73,8 \%$ responden berpengetahuan kurang baik.

d. Sesudah diberikan metode make a match hasil nilai rata-rata statistik $75,8 \%$ berpengetahuan baik dikarenakan responden sudah paham dengan metode pembelajaran make a match sehingga meningkatkan aktfitas responden dalam proses belajar.

e. Perbandingan antara kedua metode pembelajaran tipe jigsaw dan metode pembelajaran tipe make a match penulis menyatakan bahwa kedua metode pembelajaran tersebut sangat meningkat secara signifikan terhadap pengetahuan responden, tetapi dilihat dari nilai statistic lebih efektiv metode pembelejaran make a match karena metode pembelajaran ini berpengaruh terdahap keaktifan responden dalam proses belajar.

\section{DAFTAR PUSTAKA}

Depertemen Kesehatan Republik Indonesia, 2014

Fitriyah, I. (2014). Gambaran Perilaku Higiene Menstruasi pada Remaja Putri di Sekolah Dasar Negeri di Wilayah Puskesmas Pisangan. Skripsi Universitas Islam Negeri Syrif Hidayatullah Jakarta

Hidayah. N, Suharno, I. M. (2017). The Use of Cooperative Learning of Jigsaw-Type and Make A Match Type to Improve Students Activity. Nur Aini Wahyu Hidayah Suharno Mintasih Indriayu, $4(1), 25-30$.

Hijrihani, C., \& Wutsqa, D. (2015). Keefektifan Cooperative Learning Tipe Jigsaw dan STAD Ditinjau dari Prestasi Belajar dan Kepercayaan Diri Siswa. Pythagoras: Jurnal Pendidikan Matematika, $\quad 10(1), \quad 1-14$. doi:https://doi.org/10.21831/pg.v10i1.9091

Kementerian Kesehatan Indonesia, 2014. Informasi Kementerian Kesehatan Situasi Kesehatan Reproduksi

Laili Bestari P, Esti Y, Praba D R. 2019. Pendidikan Kesehatan Metode Jigsaw dan Make a Match dalam Meningkatkan Perilaku Pencegahan Fluor Albus pada Remaja Pondok Pesantren. Pediomaternal Nursing Journal, 5(1), 109-118. http://dx.doi.org/10.20473/pmnj.v5i1.12364 
Ambo Sengngeng et al, Efektivitas Metode Jigsaw Dibandingkan Metode Make a Match dalam Pengetahuan Personal Hygiene Saat Menstruasi: Studi Literatur

Leyva-Moral JM, Riu Camps M. Teaching research methods in nursing using Aronson's Jigsaw Technique. A cross-sectional survey of student satisfaction. Nurse Educ Today. 2016;40:78-83.

Notoatmodjo, S. (2010). Promosi Kesehatan dan Perilaku Kesehatan. Jakarta: Rineka Cipta

Paramita, I., Utami, N. R.., Isnaeni, W. (2012). Penggunaan Model Cooperative Learning Type Make-A-Match Terhadap Hasil Belajar Sistem Gerak. Journal of Biology Education, 1(3). https://doi.org/10.15294/jbe.v1i3.1541

Prayitno, 2014. Buku Lengkap Keprawatan Organ Wanita. Yogyakarta: Saufa

Riskesdas Provinsi Jambi, 2018

Să̆söz, Ömer \& Karatas, Ozcan \& Turel, V\& Yildiz, $M$ \& Kaya, Ercan. (2015). Effectiveness of Jigsaw learning compared to lecture-based learning in dental education. European journal of dental education : official journal of the Association for Dental Education in Europe. 21. 10.1111/eje.12174.

Santra, S. (2017). Assessment of knowledge regard ing menstruation and practices related to maintenance of menstrual hygiene among the women of reproductive age group in a slum of Kolkata , West Bengal , India. International Journal of Community Medicine and Public Health, 4(3), 708-712. https://doi.org/10.18203/2394-6040. ijcmph20170744

Souvignier, Elmar \& Kronenberger, Julia. (2008). Cooperative learning in third graders' jigsaw groups for mathematics and science with and without questioning training. The British journal of educational psychology. 77. 755-71. 10.1348/000709906X173297.

Sumarni, S., \& Wardani, H. (2019). Pengaruh Model Pembelajaran Kooperatif Tipe Jigsaw Terhadap Hasil Belajar Mata Kuliah Asuhan Kebidanan Komunitas. Jurnal Ilmiah Kesehatan Sandi Husada, 10(2), 90-94. Retrieved from https://akper-sandikarsa.ejournal.id/JIKSH/article/view/120

Wakhidah, U, Wijayanti, 2014. Hubungan tingkat pengetahuan remaja putri tentang infeksi genitalia eksterna dan perilaku vulva hygiene kelas XI di MAN 1 Surakarta. Jurnal Kebidanan

Zakir, M. (2016). Pengetahuan Remaja Putri Tentang Kebersihan Alat Genitalia Saat Menstruasi. Jurnal Keperawatan, $\quad 1, \quad$ XII. https://ejurnal.poltekkestjk.ac.id/index.php/JKEP/ article/view/368/340.

Zolekhah, D., Shanti, E., \& Barokah, L. (2020). Efektivitas Pelatihan Kader Posyandu Dalam Penggunaan Buku KIA Dengan Metode Make a Match. Journal for Quality in Women's
Health, 3(1), 9-14. https://doi.org/10.30994/jqwh.v3i1.42 